\title{
Anorectal Manometry in Defecatory Disorders: A Comparative Analysis of High-resolution Pressure Topography and Waveform Manometry
}

\author{
Yeong Yeh Lee, ${ }^{1,2}$ Askin Erdogan, ${ }^{1}$ Siegfried Yu, ${ }^{1}$ Annie Dewitt, ${ }^{1}$ and Satish S C Rao ${ }^{1 *}$ \\ ${ }^{I}$ Section of Gastroenterology and Hepatology, Augusta University, Augusta, GA, USA; and ${ }^{2}$ School of Medical Sciences, Universiti Sains \\ Malaysia, Kota Bahru, Kelantan, Malaysia
}

\section{Background/Aims}

Whether high-resolution anorectal pressure topography (HRPT), having better fidelity and spatio-temporal resolution is comparable to waveform manometry (WM) in the diagnosis and characterization of defecatory disorders (DD) is not known.

\section{Methods}

Patients with chronic constipation (Rome III) were evaluated for DD with HRPT and WM during bearing-down "on-bed" without inflated rectal balloon and "on-commode (toilet)" with $60-\mathrm{mL}$ inflated rectal balloon. Eleven healthy volunteers were also evaluated.

\section{Results}

Ninety-three of 117 screened participants (F/M = 77/16) were included. Balloon expulsion time was abnormal (> 60 seconds) in $56 \%$ (mean 214.4 seconds). A modest correlation between HRPT and WM was observed for sphincter length $(R=0.4)$ and likewise agreement between dyssynergic subtypes $(\kappa=0.4)$. During bearing down, 2 or more anal pressure-segments (distal and proximal) could be appreciated and their expansion measured with HRPT but not WM. In constipated vs healthy participants, the proximal segment was more expanded $(2.0 \mathrm{~cm}$ vs $1.0 \mathrm{~cm}, P=0.003)$ and of greater pressure $(94.8 \mathrm{mmHg}$ vs $54.0 \mathrm{mmHg}, P=0.010)$ during bearing down on-commode but not on-bed.

\section{Conclusions}

Because of its better resolution, HRPT may identify more structural and functional abnormalities including puborectal dysfunction (proximal expansion) than WM. Bearing down on-commode with an inflated rectal balloon may provide additional dimension in characterizing DD.

(J Neurogastroenterol Motil 2018;24:460-468)

Key Words

Anal canal; Constipation; Defecation; Gastrointestinal motility; Manometry

Received: July 3, 2017 Revised: February 3, 2018 Accepted: March 26, 2018

(-) This is an Open Access article distributed under the terms of the Creative Commons Attribution Non-Commercial License (http://creativecommons. org/licenses/by-nc/4.0) which permits unrestricted non-commercial use, distribution, and reproduction in any medium, provided the original work is properly cited.

*Correspondence: Satish S C Rao, MD, PhD, FRCP, AGAF, FACG

Department of Medicine, Section of Gastroenterology and Hepatology, Medical College of Georgia, Augusta University, 1120 15th Street, BBR 2538, Augusta, GA 30912, USA

Tel: +1-706-721-2238, Fax: +1-706-721-0331, E-mail: srao@augusta.edu 


\section{Introduction}

Defecatory disorders (DD), a prevalent condition associated with constipation, require anorectal testing to identify dyssynergic defecation and other rectal structural abnormalities. ${ }^{1}$ Anorectal manometry is the preferable test for $\mathrm{DD}$ and conventional waveform manometry (WM) has been the gold standard until recently when high-resolution (HR) technology becomes available. ${ }^{2}$ The greater fidelity and spatio-temporal topography of HR anorectal manometry allows better delineation of anatomy and physiological details that is not possible with WM, however, this has not been adequately studied or compared.

Four types (I-IV) of manometric patterns of DD have been described by Rao et $\mathrm{al}^{3}$ and Rao and Singh ${ }^{4}$ with WM. These 4 patterns can also be observed with HR topographic display. ${ }^{2}$ Most recently, a study using complex principal components analysis of pressure data from HR anorectal manometry classified patients with DD into 3 distinct motor patterns ${ }^{5,6}$ which were similar to the Rao et $\mathrm{al}^{3}$ subtypes. Besides diagnosis and classifying dyssynergic patterns, HR pressure topography (HRPT) can reveal the differential involvement of anal sphincteric components that may explain the underlying pathophysiology of $\mathrm{DD} .^{7-9}$

The HR anorectal manometry system provides a dual display of anorectal pressure changes; a topographic plot and a manometric plot that can be viewed by toggling between the 2 modes. However, DD has been mainly characterized using WM. The aim of this study is to compare manometric assessment of DD and its subtypes using both HRPT and WM, and to determine the correlation between techniques and if there are other additional advantages of HRPT over WM.

\section{Materials and Methods}

\section{Study Participants}

Prospective patients referred to a tertiary center with chronic symptoms of constipation (for at least 6 months) were evaluated for participation. Besides anorectal manometry, all participants underwent colonoscopy, flexible sigmoidoscopy or barium enema, and blood tests to exclude any underlying mucosal or metabolic diseases that could cause constipation. For comparison, 11 healthy participants without chronic constipation as determined by the Rome III questionnaire underwent the same study protocol, including the above-mentioned investigations to exclude organic disorders. All participants had informed consent on study entry. The protocol and informed consent form were approved by the Institutional Review Board of Georgia Regents University, Augusta, United States.

Participants with constipation were included into the study if they fulfilled the Rome III criteria for functional defecatory disorder. Briefly, participants fulfil the symptom criteria for functional constipation and 2 or more of the physiologic criteria including (1) presence of 1 of the 4 DD patterns (I-IV patterns) previously described by Rao et $\mathrm{al}^{3}$ and Rao and Singh, ${ }^{4}$ (2) inability to expel a balloon or stool-like device, (3) a prolonged colonic transit time, and (4) inability to expel barium or $>50 \%$ retention during defecography.

Participants were excluded if their predominant symptom was abdominal pain or bowel habit changes suggestive of irritable bowel syndrome or fecal incontinence other than that associated with fecal impaction, complicated pelvic floor surgery, spinal cord injury or stroke, previous abdominal surgery (except for cholecystectomy, hysterectomy, and appendectomy), and significant psychiatric or other co-morbid illnesses.

\section{Anorectal Manometry}

\section{Anorectal manometry system}

All participants underwent anorectal manometry using the same system (Given Imaging, Yoqneam, Israel) of which the technical details have been published previously. ${ }^{2}$ Briefly, the $4.2 \mathrm{~mm}$ probe with 10 sensors at 6-mm interval was placed along the anal canal, and 2 other sensors housed in a 4-cm latex balloon were placed into the rectum. The sector pressures from these 12 sensors were averaged to obtain a single mean value at each location. Each sensing element records pressure transients excess of $6000 \mathrm{mmHg} /$ sec and is accurate to within $1 \mathrm{mmHg}$ of atmospheric pressure. The probe was connected to a proprietary recorder (Manoscan 360AR, Given Imaging) and the data recorded with the acquisition software at a frequency of $35 \mathrm{~Hz}$. Due to the effect of "thermal drift," the probe was calibrated in a warm water-bath each week and thermal compensation applied to the data during analysis to compensate for the drift. ${ }^{10}$

\section{Protocol of anorectal manometry}

Approximately 3 minutes of familiarization was allowed lying on a bed in the left lateral position. This was followed by 1 minute of resting pressure assessment. Participants were then asked to squeeze the anal sphincter twice with 30-second interval of rest period and squeeze-hold for 30 seconds for assessment of endurance. 
Abdomino-pelvic reflex was assessed by asking the participant to blow-up a party balloon twice separated by 30 seconds rest period. Subsequently, participants were asked to bear down "on-bed" without inflated rectal balloon as if to defecate for 2 or 3 occasions at 1-minute intervals. To simulate physiological defecation, participants were asked to attempt bearing down "on-commode or toilet." The commode is a mobile unit, with soft seat cushion and has a removable dry collection pail. The procedure was carefully explained to the participant beforehand. The probe was secured in place with tapes and extreme care of the probe was taken when moving the participant from the bed to the commode. Once on the commode, the rectal balloon was inflated with $60-\mathrm{mL}$ of water to simulate stool. The participant was then asked to perform the usual bearing down maneuver. After completion of the test, the participant was then moved back to the bed and the probe removed after deflation of the balloon.

\section{Acquisition of anorectal pressure}

Pressure parameters were derived from the proprietary software (Manoview AR v1.0; Given Imaging). Rectal pressure was measured by the proximal sensor within the rectal balloon. Anal pressures were measured by several sensors that straddled the anal canal but the e-sleeve option allowed a single value at every time point. During resting and squeeze maneuvers, e-sleeve identified the maximum of all pressures recorded by anal sensors at any time point. On the other hand, for bearing down, the e-sleeve identified the most positive (or least negative) difference between rectal and anal pressures over 30 seconds of maneuver. For WM, 30 seconds e-sleeve values of the distal $2 \mathrm{~cm}$ of the anal canal was used to determine mean resting, squeeze, and bearing down pressures. For HRPT, 30 seconds e-sleeve values of all sensors straddling the anal canal was used to calculate the mean pressures of resting, squeeze, and bearing down pressures.

\section{Anorectal pressure analysis during bearing down}

The anal sphincter at rest and during bear down on-bed and on-commode were determined, with upper and lower baseline limits being the limits of anal sphincter length, measured in mean $\pm \mathrm{SD}$. When there was anal sphincter lengthening during bearing down (Fig. 1), the proximal anal segment $\left(\mathrm{p}_{1}\right)$ was defined as the pressure segment above the upper baseline limit of the anal high-pressure zone, and the distal segment $\left(\mathrm{p}_{2}\right)$ was defined as the pressure segment between upper baseline limit and lower limit of the anal highpressure zone. Mean pressure was derived using the software for

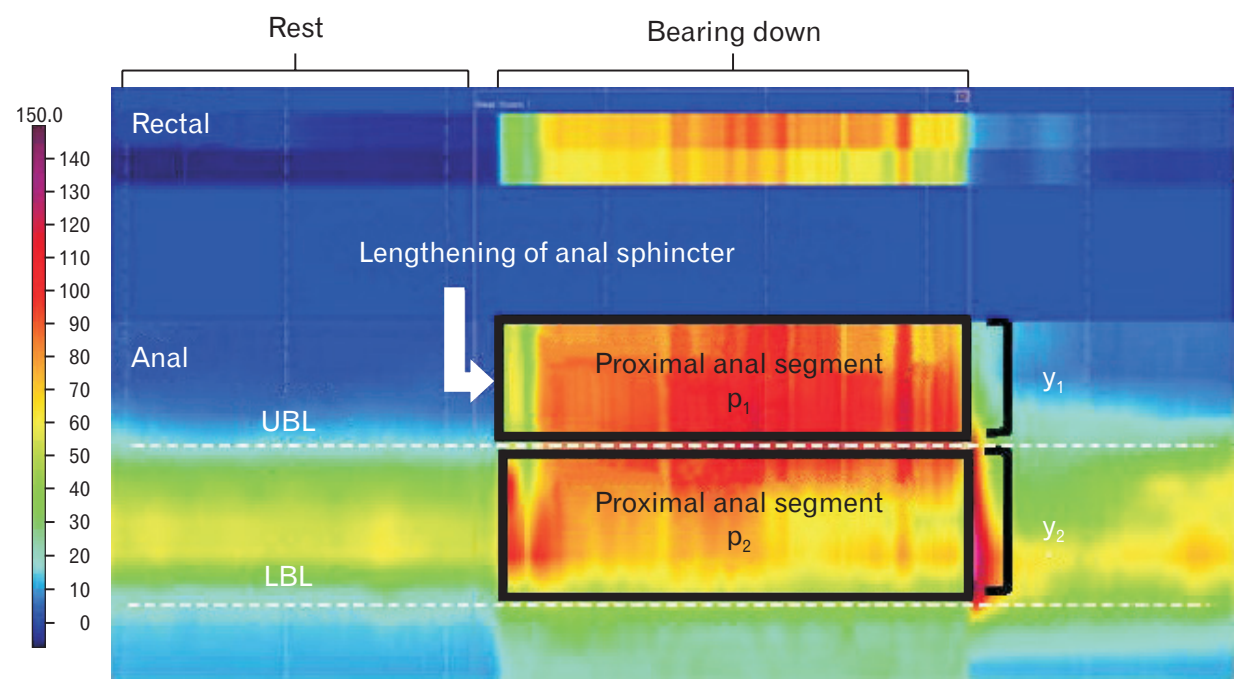

Figure 1. Color topography but not conventional lines is able to discern 2 or more different anal pressure segments (proximal and distal) during bearing down maneuvers. The proximal anal segment probably signifies the lengthening of anal sphincter during bearing down. The anal sphincter at rest and during bear down on-bed and on-commode were determined, with upper baseline limits (UBL) and lower baseline limits (LBL) being the limits of anal sphincter length, measured in mean $\pm \mathrm{SD}$. The proximal anal segment was defined as the pressure segment above the upper baseline limit of anal high-pressure zone, and the distal segment defined as the pressure segment between upper baseline limit and lower limit of the anal high-pressure zone. Mean pressure was derived using software for both pressure segments ( $\mathrm{p}_{1}$ for proximal segment and $\mathrm{p}_{2}$ for distal segment). Length of the proximal anal segment $\left(y_{1}\right)$ was defined as distance between upper baseline limit of anal high-pressure zone to the uppermost limit measurable by sensor of the probe, and length of distal anal segment $\left(y_{2}\right)$ as the distance between upper baseline limit and lower limit of the anal pressure zone. 
both pressure segments. Length of proximal anal segment $\left(\mathrm{y}_{1}\right)$ was defined as the distance between the upper baseline limit of anal high-pressure zone to the uppermost limit measurable by the sensor of the probe, and length of distal segment $\left(\mathrm{y}_{2}\right)$ as the distance between the upper baseline limit and lower limit of the anal pressure zone.

In addition to DD patterns described by Rao et $\mathrm{al}^{3}$ and Rao and Singh, ${ }^{4}$ the 3 subtypes based on principal components analysis recently described by Ratuapli et $\mathrm{al}^{5}$ (high anal, hybrid, and low rectal) were also determined (Fig. 2). Type I was similar with high anal subtype, type II similar with hybrid subtype and type IV similar with low rectal subtype, but a similar description by Ratuapli et $\mathrm{al}^{5}$ for Rao's type III was not available. During bearing down, an intra-rectal pressure $\leq 45 \mathrm{mmHg}$ was defined as inadequate and a percentage anal relaxation of $\leq 20 \%$ was defined as abnormal. ${ }^{11}$ Defecation index ${ }^{3}$ and rectoanal pressure gradient (RAPG), ${ }^{12}$ both measures for coordinated effort of the rectum and anus, were also calculated.

\section{Balloon Expulsion Test}

After anorectal manometry, participants were asked to attempt expulsion on-commode in their own privacy of a $50-\mathrm{mL}$ water-filled 4-cm balloon in their rectum and the test was stopped if the balloon was not expelled by 5 minutes. A balloon expulsion time (BET) $\geq$ 60 seconds was considered as abnormal.

\section{Statistical Methods}

Both HRPT and WM were examined separately by 2 investigators (Yeong Yeh Lee and Askin Erdogan) independently using the proprietary software, Manoview Analysis Program (Given Imaging). Each HRPT and WM tracing was given a number and with simple randomization using a number table, and the investigators were randomly assigned to either tracing of HRPT or WM. To further reduce ascertainment bias, results were not disclosed to each investigator until data analyses. Both investigators had good agreement levels $(\kappa$ coefficient $=0.8)$ before starting the study. Any disagreement on analysis of tracing was resolved individually with a third senior investigator (Satish Rao).

All data were presented as mean $\pm \mathrm{SD}$ unless otherwise stated. Correlations between HRPT and WM on manometric parameters were determined with correlation analysis (Pearson, R or Spearman, $r$ coefficient). Comparison of lengths and pressures of anal sphinc-

\section{A}

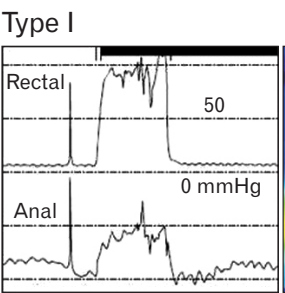

Type III

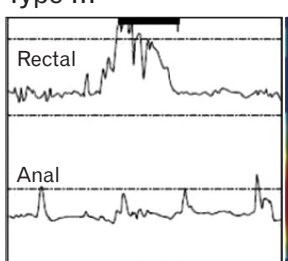

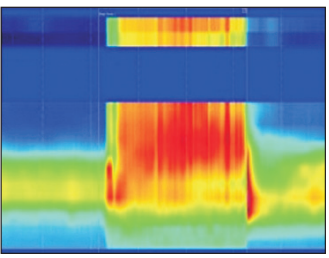

Type IV
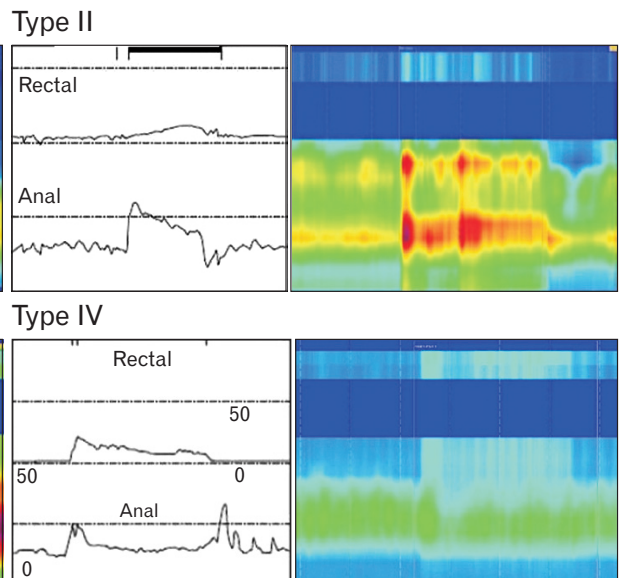

B

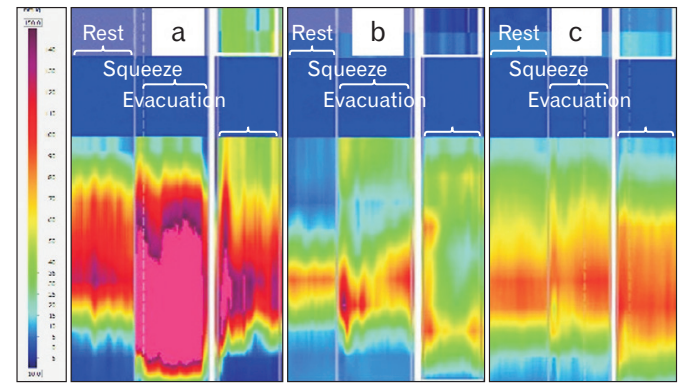

Figure 2. The 4 types (I-IV) of dyssynergic defecation patterns (A) previously described by Rao et $\mathrm{al}^{3}$ and Rao and Singh ${ }^{4}$ are illustrated in conventional lines and color topographic forms. (B) The 3 defecatory subtypes based on principal components analysis recently described by Ratuapli et al, ${ }^{5}$ ie, [a] high anal, [b] hybrid, and [c] low rectal. 
ter between constipated and healthy subjects were made using $t$ test. For all statistical tests, $P<0.05$ was considered significant.

\section{Results}

\section{Characteristics of Study Participants}

A total of 117 consecutive participants with constipation were screened and eventually 93 participants were included into the study. Of those excluded participants, 9 were because of absence of defecatory disorder or failed BET, 7 were due to incomplete examination or technical issues with the anorectal manometry system, and the rest because of exclusion criteria.

Of the 93 participants with defecatory disorders (F/M, 77/16; mean age $48 \pm 17$ years), $77 \%$ had straining during defecation, $66 \%$ had hard stools, $83 \%$ with incomplete evacuation, and $57 \%$ reported fewer than 3 defecations/week. In addition, more than $80 \%$ of patients claimed the use of enemas. Slightly above half (56\%) had abnormal BET > 60 seconds (F/M, 43/8; mean BET time of $214.4 \pm 100.1$ seconds). All healthy participants (M/F, 5/6; age range 22-55 years) had normal BET and without DD. There were no encounters of probe damage during the bearing down maneuver on-commode.

\section{Correlation Between Pressure Parameters and Agreement of Dyssynergic Defecation Patterns}

Pressure parameters measured by HRPT and WM and their correlations are presented in Table 1. There were significant correlations between HRPT and WM for resting anal pressures, maximum squeeze, and sustained/endurance squeeze (coefficient ranged 0.8 to 0.9 , all $P<0.001)$, except for anal length $(\mathrm{R}=0.4, P<$ 0.001). Between the 2 techniques of HRPT and WM, both rectal and anal pressures correlated for bearing down on-bed (both $r=$ $0.8, P<0.001$ ), but not during bearing down on-commode (both $r=0.1$ and $P=0.300$ ). On the other hand, with HRPT, bearing down on-commode with an inflated rectal balloon, supposedly more physiological, correlated with bearing down on-bed for rectal pressure but modest correlation for anal pressures $(r=0.7$ and $r=0.5$ respectively, both $P<0.001)$. Both defecation index $(r=0.6, P<$ $0.001)$ and RAPG $(r=0.7, P<0.001)$ correlated between the 2 techniques. Dyssynergic patterns determined by HRPT and WM and their $\kappa$ coefficients are presented in Table 1 . Between the 2 techniques of HRPT and WM, agreement between DD patterns was poor $(\kappa=0.4, P<0.001)$, and likewise agreement between DD patterns described by Rao et $\mathrm{al}^{3}$ and Ratuapli et $\mathrm{al}^{5}(\kappa=0.4, P$ $<0.001$ ) (data not shown).

Table 1. Correlation Analysis of Pressure Metrics and Agreement Levels of Dyssynergic Patterns Between High-resolution Pressure Topography and Waveform Manometry

\begin{tabular}{|c|c|c|c|c|}
\hline Parameters & HRPT & WM & Analysis $^{\mathrm{a}, \mathrm{b}}$ & $P$-value \\
\hline Rest (mean [SD], mmHg) & $77.2(27.0)$ & $72.1(26.7)$ & $0.8^{\mathrm{a}}$ & $<0.001$ \\
\hline Length (mean $[\mathrm{SD}], \mathrm{cm})$ & $3.6(0.8)$ & $3.8(0.8)$ & $0.4^{\mathrm{a}}$ & $<0.001$ \\
\hline Maximum squeeze (median $[\mathrm{IQR}], \mathrm{mmHg}$ ) & $156.2(103.7)$ & $148.9(94.9)$ & $0.9^{\mathrm{a}}$ & $<0.001$ \\
\hline Sustained squeeze (mean [SD], mmHg) & $89.0(33.1)$ & $94.3(34.6)$ & $0.9^{\mathrm{a}}$ & $<0.001$ \\
\hline Bear down on-bed, rectal (median $[\mathrm{IQR}], \mathrm{mmHg}$ ) & $42.3(32.2)$ & $42.7(31.7)$ & $0.8^{\mathrm{a}}$ & $<0.001$ \\
\hline Bear down on-bed, anal (median [IQR], mmHg) & $61.2(25.6)$ & $62.2(32.3)$ & $0.8^{\mathrm{a}}$ & $<0.001$ \\
\hline Bear down on-commode, rectal (median $[\mathrm{IQR}], \mathrm{mmHg}$ ) & $105.5(155.4)$ & $102.3(162.0)$ & 0.3 & 0.010 \\
\hline Bear down on-commode, anal (median [IQR $], \mathrm{mmHg}$ ) & $80.8(157.0)$ & $77.8(171.1)$ & 0.1 & 0.300 \\
\hline DI (median [IQR $]$ ) & $0.7(0.4)$ & $0.7(0.5)$ & $0.6^{\mathrm{a}}$ & $<0.001$ \\
\hline RAPG (median [IQR], mmHg) & $-17.8(-22.9)$ & $-16.6(-32.4)$ & $0.7^{\mathrm{a}}$ & $<0.001$ \\
\hline DD patterns, type 1 (n [\%]) & $21(23.1)$ & $30(33.0)$ & & \\
\hline DD patterns, type $2(\mathrm{n}[\%])$ & $28(30.8)$ & $27(29.7)$ & $0.4^{\mathrm{b}}$ & $<0.001$ \\
\hline DD patterns, type $3(\mathrm{n}[\%])$ & $14(15.4)$ & $13(14.3)$ & & \\
\hline DD patterns, type 4 (n [\%]) & $28(30.8)$ & $21(23.1)$ & & \\
\hline
\end{tabular}

${ }^{\mathrm{a} C o r r e l a t i o n}$ analysis: Pearson's or Spearman rho correlation co-efficient, depending on normality of data. ${ }^{\mathrm{b}}$ Agreement analysis: kappa coefficient.

HRPT, high-resolution pressure topography; WM, waveform manometry; IQR, interquartile range; DI, defecation index; RAPG, rectoanal pressure gradient; DD, dyssynergic defecation.

$P<0.05$ as significant. 
Table 2. Characteristics of Anal Expansion Observed With High-resolution Pressure Topography During Bearing Down in Constipated Versus Healthy Individuals

\begin{tabular}{lccc}
\multicolumn{1}{c}{ Parameters } & $\begin{array}{c}\text { Healthy } \\
(\mathrm{n}=11)\end{array}$ & $\begin{array}{c}\text { Defecatory disorders } \\
(\mathrm{n}=93)\end{array}$ \\
\hline On-bed without rectal balloon & & & $P$-value \\
Total anal length (y2 + y1) & $4.5(0.7)$ & $4.5(0.6)$ & 0.900 \\
Anal length (y2), distal (mean [SD], cm) & $3.3(0.6)$ & $2.4(0.4)$ & 0.004 \\
Anal length (y1), proximal (mean [SD], cm) & $1.2(0.7)$ & $1.9(0.3)$ & 0.050 \\
Anal pressure (p2), distal (mean [SD], mmHg) & $58.2(12.6)$ & $68.2(24.0)$ & 0.300 \\
Anal pressure (p1), proximal (mean [SD], mmHg) & $41.5(19.7)$ & $48.5(23.9)$ & \\
On-commode with rectal balloon & $4.2(0.6)$ & $4.8(0.4)$ & 0.600 \\
Total anal length (y2 + y1) (mean [SD], cm) & $3.2(0.9)$ & $2.8(0.4)$ & 0.003 \\
Anal length (y2), distal (mean [SD], cm) & $1.0(0.7)$ & $8.0(0.5)$ & 0.100 \\
Anal length (y1), proximal (mean [SD], cm) & $60.4(18.5)$ & $94.8(21.3)$ & 0.004 \\
Anal pressure (p2), distal (mean [SD], mmHg) & $54.0(6.8)$ & 0.010 \\
Anal pressure (p1), proximal (mean [SD], mmHg) & & \\
\hline
\end{tabular}

$P<0.05$ as significant.

\section{Expansion of Anal Sphincter During Bearing Down in Constipated Participants}

HRPT but not WM was able to discern 2 or more different anal pressure segments (proximal, $\mathrm{p}_{1}$ and distal, $\mathrm{p}_{2}$ ) during bearing down on-bed and on-commode (Fig. 1). In addition, the anal sphincter was observed to expand in length during bearing down with HRPT but not with WM. Mean total length $\left(\mathrm{y}_{1}+\mathrm{y}_{2}\right)$ of the anal sphincter was greater during bearing down than at rest both on-bed $(4.4 \mathrm{~cm} \pm 0.7 \mathrm{~cm}$ vs $3.6 \mathrm{~cm} \pm 0.8 \mathrm{~cm}, P<0.001)$ and oncommode $(4.6 \mathrm{~cm} \pm 0.7 \mathrm{~cm}$ vs $3.6 \mathrm{~cm} \pm 0.8 \mathrm{~cm}, P<0.001)$. Distal segment $\left(\mathrm{y}_{2}\right)$ was longer than proximal segment $\left(\mathrm{y}_{1}\right)$ both during bearing down on-bed $(2.8 \mathrm{~cm} \pm 0.7 \mathrm{~cm}$ vs $1.7 \mathrm{~cm} \pm 0.7 \mathrm{~cm}, P<$ $0.001)$ and on-commode $(2.7 \mathrm{~cm} \pm 0.7 \mathrm{~cm}$ vs $1.8 \mathrm{~cm} \pm 0.8 \mathrm{~cm}$, $P<0.001)$. The observed differences in length between segments also corresponded to differences in mean anal pressure between segments where the anal pressure was greater in the longer distal segment $\left(\mathrm{y}_{2}\right)$ vs the shorter proximal segment $\left(\mathrm{y}_{1}\right)(62.9 \mathrm{mmHg} \pm$ $22.2 \mathrm{mmHg}$ vs $53.8 \mathrm{mmHg} \pm 23.9 \mathrm{mmHg}, P<0.001)$ during bearing down on-bed.

\section{Anal Sphincter Expansion in Healthy Versus Constipated Individuals}

Anal sphincter expansion observed with HRPT in constipated participants was also present in healthy individuals but different characteristics were observed (Table 2). Total anal length $\left(\mathrm{y}_{1}+\mathrm{y}_{2}\right)$ was significantly longer in the on-commode than on-bed in constipated $(P=0.003)$ but not healthy participants $(P=0.900)$. The proximal segment $\left(\mathrm{y}_{1}\right)$ was twice longer in constipated vs healthy participants during bearing down on-commode $(2.0 \mathrm{~cm} \pm 0.5 \mathrm{~cm}$ vs $1.0 \mathrm{~cm} \pm 0.7 \mathrm{~cm}, P=0.003)$ but not on-bed $(P=0.050)$. On the other hand, a longer distal anal segment $\left(\mathrm{y}_{2}\right)$ was observed in healthy vs constipated participants during bearing down on-bed $(P=0.004)$ but not on-commode $(P=0.100)$. Anal pressures in the proximal $\left(\mathrm{p}_{1}\right)$ and distal $\left(\mathrm{p}_{2}\right)$ segments of bearing down oncommode were increased in constipated vs healthy participants $(P$ $=0.010$ and $P=0.004$, respectively) but not during bearing down on-bed ( $P=0.6$ and $P=0.3$, respectively).

\section{Anal Expansion in Defecatory Disorders With Normal Versus Abnormal Balloon Expulsion Time}

Table 3 shows the pressure metrics and anal expansion features in defecatory disorders with normal vs abnormal BETs. There were no differences in pressure metrics in those with normal vs abnormal BETs (all $P>0.1$ ). During bearing down on-bed, there were also no differences observed in anal expansion between normal and abnormal BETs (all $P>0.05$ ). Likewise, during bearing down on-commode, no differences were observed in normal vs abnormal BETs (all $P>0.2$ ).

\section{Discussion}

The main findings from the current study include the following; (1) between HRPT and WM, significant correlations were observed of pressure metrics except for sphincter length and pressure metrics during bearing down on-commode, (2) during bearing down, HRPT but not WM can identify 2 or more anal pressure 
Table 3. Characteristics of Pressure Metrics and Anal Expansion in Defecatory Disorders With Normal Versus Abnormal Balloon Expulsion Test

\begin{tabular}{|c|c|c|c|}
\hline Parameters & $\begin{array}{c}\text { Normal BET }<60 \mathrm{sec} \\
\qquad(\mathrm{n}=40)\end{array}$ & $\begin{array}{c}\text { Abnormal } \mathrm{BET} \geq 60 \mathrm{sec} \\
(\mathrm{n}=51)\end{array}$ & $P$-value \\
\hline \multicolumn{4}{|l|}{ Pressure metrics } \\
\hline Rest (mean [SD], mmHg) & $72.0(24.2)$ & $81.3(28.5)$ & 0.100 \\
\hline Maximum squeeze (median [IQR], mmHg) & $152.0(131.8)$ & $156.7(105.4)$ & 0.200 \\
\hline Sustained squeeze (mean [SD], mmHg) & $88.4(33.7)$ & $89.5(33.0)$ & 0.900 \\
\hline DI (median [IQR]) & $0.8(0.6)$ & $0.7(0.3)$ & 0.100 \\
\hline RAPG (median [IQR], mmHg) & $-13.4(-23.4)$ & $-21.5(-24.6)$ & 0.100 \\
\hline \multicolumn{4}{|l|}{ Anal sphincter expansion characteristics: on-bed } \\
\hline Rectal (median [IQR], mmHg) & $46.5(35.2)$ & $41.1(29.9)$ & 0.300 \\
\hline Anal (median [IQR], mmHg) & $59.4(22.4)$ & $62.6(25.2)$ & 0.300 \\
\hline Anal pressure (P2), distal (mean [SD], mmHg) & $60.3(19.4)$ & $65.2(23.6)$ & 0.300 \\
\hline Anal pressure $(\mathrm{P} 1)$ proximal (mean $[\mathrm{SD}], \mathrm{mmHg})$ & $51.3(18.7)$ & $52.6(29.9)$ & 0.400 \\
\hline \multicolumn{4}{|l|}{ Anal sphincter expansion characteristics: on-commode } \\
\hline Rectal (median [IQR], mmHg) & $106.0(151.6)$ & $102.5(143.4)$ & 0.300 \\
\hline Anal (median [IQR], mmHg) & $76.7(148.8)$ & $82.8(155.8)$ & 0.900 \\
\hline Anal pressure (P2), distal (mean [SD], mmHg)) & $79.9(35.3)$ & $78.4(25.1)$ & 0.800 \\
\hline Anal pressure $(\mathrm{P} 1)$, proximal (mean $[\mathrm{SD}], \mathrm{mmHg})$ & $86.7(29.6)$ & $82.8(34.1)$ & 0.600 \\
\hline
\end{tabular}

BET, balloon expulsion test; IQR, interquartile range; DI, defecation index; RAPG, rectoanal pressure gradient.

$P<0.05$ as significant.

segments (distal and proximal), (3) there is a difference in characteristics of anal pressure segments during bearing down between healthy and constipated participants, especially with additional test of bearing down on-commode (toilet) with an inflated rectal balloon, however, and (4) there is no difference between abnormal vs normal BETs in pressure metrics and anal expansion characteristics regardless of bearing down on-bed or on-commode.

Pressures derived from solid state and water-perfused anorectal manometry were shown in studies to correlate well, although these studies found higher anal sphincter pressures and a shorter sphincter with solid state HR manometry. ${ }^{13-16}$ In these correlation studies, both techniques were performed on the same participants but on separate days, with intervals not clearly defined, and hence there is a potential for measurement bias due to changes in the anorectal physiology over time. Other factors to consider that might affect measurement include catheter design, number of sensors and diameter of the catheter, but these were eliminated with the current study design. In our study, to reduce bias, both HRPT and WM were performed in the same patients, at the same time with the same machine, but the tracings were analyzed by 2 experienced investigators at random. Our results indicate a good correlation in pressure metrics between the 2 techniques except for the length of sphincter and pressures during the bearing down on-commode. The agreement of DD types between the 2 techniques were poor, in keeping with a recently published data, ${ }^{16}$ and this is probably because of better resolution of HRPT. Likewise, agreement between DD patterns described by Rao et al, ${ }^{3}$ Rao and Singh, ${ }^{4}$ and Ratuapli et $\mathrm{al}^{5}$ (Fig. 2) was poor and this suggests that they are not directly comparable.

Due to a better resolution of HRPT that captures data along the whole length of the sphincter, it can discriminate 2 or more anal pressure segments and their lengths that was not discernible with WM (Fig. 1). In both constipated and healthy participants, we observed a longitudinal expansion of anal high-pressure zone as evidenced by an increase in the length during bearing down when compared to its resting length. It may represent recruitment of more muscle during attempted defecation and or lengthening of anal sphincter muscles including puborectalis, external anal sphincter and longitudinal muscles that has been shown to occur during "normal" defecation. ${ }^{17,18}$ This process seems to be "exaggerated" in constipated compared to healthy participants by causing an expansion and increase in pressure of the proximal high-pressure zone. Whether this is unique to DD and a cause or effect of constipation merits further studies.

Interestingly, this lengthening may potentially increase the muscle mass and pose further resistance to the outlet causing functional obstruction to flow of stool. This expansion in the proximal segment is likely to be a result of recruitment and anterior pull of puborectalis muscle acting on the cranial part of the anal canal ${ }^{7}$ although longitudinal muscles may also be involved in a synergistic fashion. Recently 8 subtypes of dyssynergia have been described us- 
ing HRPT and this includes 2 subtypes where puborectalis appears to be dyssynergic whereas external anal sphincter shows normal relaxation. ${ }^{19}$ This indicates that the puborectalis muscle rather than the longitudinal muscles may be more important in characterizing subtypes of DD. Indeed, abnormal contractions of the puborectalis muscle are often seen in obstructed defecation, and patients with these abnormal contractions seem to respond favorably to biofeedback treatment. ${ }^{20,21}$ Further studies are needed to ascertain the role of puborectalis muscle in different DD patterns, especially type I and III and their responses to biofeedback therapy.

Our study suggests that the HRPT provides assessment of function of the puborectalis and longitudinal muscles in constipated patients. In healthy subjects, the length of proximal segment $\left(\mathrm{y}_{1}\right)$ was similar during bearing down on-bed or on-commode but in constipated participants, the proximal segment $\left(\mathrm{y}_{1}\right)$ was significantly longer and of higher pressure on-commode than on-bed. The distal anal segment $\left(\mathrm{y}_{2}\right)$ was longer on-bed in healthy vs constipated patients because of lesser proximal segment recruitment among the healthy compared to constipated patients. The proximal segment recruitment was "enhanced" with bearing down on-commode, and this additional test on-commode seems to bring out abnormality in puborectalis function more than compared to bearing down onbed. Furthermore, bearing down on-commode with inflated rectal balloon is probably more physiological compared to bearing down on-bed without inflated rectal balloon. Inflation of the rectal balloon during bearing down on-commode to simulate stool may therefore add another physiological dimension to this test. DD was found to persist when the test was performed in the more physiological condition of bearing down on-commode with an inflated rectal balloon. On the other hand, besides pressure metrics, the 2 methods of bearing down did not discriminate between normal and abnormal BETs. Similar to previous studies, although abnormal BETs may indicate a greater possibility of dyssynergia, this test does not define structural and physiological mechanisms of disordered defecation, ${ }^{22}$ which is the reason why pressure metrics were similar regardless of BET. Further studies are needed to confirm if bearing down oncommode with the rectal balloon inflated is a better diagnostic test than bearing down on-bed using HRPT.

There are limitations to the study. The results were produced by the same catheter and analyzed by the same software but presented to different investigators, and thus the numerical values could be similar but it is the qualitative interpretation of data that really matters. A larger sample of healthy participants matched for age and sex might be preferable. However, we acknowledged the limitation that the differences in age between healthy and constipated partici- pants might affect pressure profiles. Likewise, the effect of possible sphincter injury on the manometric assessment of multiparous women. The description of expanded proximal anal segment might be seen by other investigators as pressure from the rectum or in case of a positive RAPG, as a normal simulated defecation maneuver. Unfortunately, our finding of expanded anal segment in constipation had not been validated using endo-anal ultrasound or other imaging techniques. Lastly, defecatory disorders are frequently seen in healthy and not just constipated subjects, but our study was not designed to compare defecatory abnormalities present in health and disease.

As a conclusion, we found a modest correlation between HRPT and WM for identifying sphincter length and dyssynergia. Because of its better resolution, HRPT may identify more structural and functional abnormalities including puborectal dysfunction than WM in patients with defecatory disorders that are associated with constipation. Bearing down on-commode with an inflated rectal balloon may provide additional dimension in characterizing constipation.

\section{Financial support: None.}

Conflicts of interest: Satish S C Rao reports no conflict of interest in the context of this report but has served as a consultant for Forest Laboratories, Ironwood Pharmaceuticals, Takeda Pharmaceuticals, Salix Pharmaceuticals, and Given Imaging. Yeong Yeh Lee, Askin Erdogan, Siegfried Yu, and Annie Dewitt report no conflicts of interest.

Author contributions: Yeong Yeh Lee, Askin Erdogan, Siegfried Yu, Annie Dewitt, and Satish S C Rao contributed equally to the study design, data collection, statistical analysis, and writing of manuscript.

\section{References}

1. Bharucha AE, Rao SSC. An update on anorectal disorders for gastroenterologists. Gastroenterology 2014;146:37-45, e2.

2. Lee YY, Erdogan A, Rao SSC. High resolution and high definition anorectal manometry and pressure topography: diagnostic advance or a new kid on the block? Curr Gastroenterol Rep 2013;15:360.

3. Rao SSC, Mudipalli RS, Stessman M, Zimmerman B. Investigation of the utility of colorectal function tests and Rome II criteria in dyssynergic defecation (Anismus). Neurogastroenterol Motil 2004;16:589-596.

4. Rao SSC, Singh S. Clinical utility of colonic and anorectal manometry in chronic constipation. J Clin Gastroenterol 2010;44:597-609.

5. Ratuapli SK, Bharucha AE, Noelting J, Harvey DM, Zinsmeister 
AR. Phenotypic identification and classification of functional defecatory disorders using high-resolution anorectal manometry. Gastroenterology 2013;144:314-322, e2.

6. Rao SSC, Hasler WL. Can high-resolution anorectal manometry shed new light on defecatory disorders? Gastroenterology 2013;144:263-265.

7. Raizada V, Bhargava V, Karsten A, Mittal RK. Functional morphology of anal sphincter complex unveiled by high definition anal manometery and three dimensional ultrasound imaging. Neurogastroenterol Motil 2011;23:1013-1019, e460.

8. Cheeney G, Remes-Troche JM, Attaluri A, Rao SSC. Investigation of anal motor characteristics of the sensorimotor response (SMR) using 3-D anorectal pressure topography. Am J Physiol Gastrointest Liver Physiol 2011;300:G236-G240.

9. Cheeney G, Nguyen M, Valestin J, Rao SSC. Topographic and manometric characterization of the recto-anal inhibitory reflex. Neurogastroenterol Motil 2012;24:e147-e154.

10. Robertson E V., Lee YY, Derakhshan MH, et al. High-resolution esophageal manometry: addressing thermal drift of the manoscan system. Neurogastroenterol Motil 2012;24:6164, e11.

11. Rao SS, Hatfield R, Soffer E, Rao S, Beaty J, Conklin JL. Manometric tests of anorectal function in healthy adults. Am J Gastroenterol 1999;94:773-783.

12. Bharucha AE, Wald A, Enck P, Rao S. Functional anorectal disorders. Gastroenterology 2006;130:1510-1518.

13. Vitton V, Ben Hadj Amor W, Baumstarck K, Grimaud J-C, Bouvier M. Water-perfused manometry vs three-dimensional high-resolution manometry: a comparative study on a large patient population with anorectal disorders. Colorectal Dis 2013;15:e726-e731.

14. Jones MP, Post J, Crowell MD. High-resolution manometry in the evaluation of anorectal disorders: a simultaneous comparison with waterperfused manometry. Am J Gastroenterol 2007;102:850-855.

15. Lee JE, Lee JS, Im HH, et al. Comparison of high resolution anorectal manometry with conventional anorectal manometry in the diagnosis of defecatory disorder caused by pelvic floor dysfunction. Gastroenterology 2010;138(suppl 1):S543.

16. Soubra M, Go JT, Valestin J, Schey R. A comparison of standard anorectal manometry vs high resolution manometry patterns in dyssynergic patients. Neurogastroenterol Motil 2013;144(suppl 1):S364-S365.

17. Shafik A. A new concept of the anatomy of the anal sphincter mechanism and the physiology of defecation: mass contraction of the pelvic floor muscles. Int Urogynecol J Pelvic Floor Dysfunct 1998;9:28-32.

18. Shafik A. A new concept of the anatomy of the anal sphincter mechanism and the physiology of defecation. III. The longitudinal anal muscle: anatomy and role in anal sphincter mechanism. Invest Urol 1976;13:271277.

19. Rao SSC, Leelasinjaroen P, Amieva-balmori M, Sharma A, Patcharatrakul T, Dewitt A. Characterization of dyssynergia phenotypes with high resolution anorectal manometry (HRAM). Gastroenterology 2016;150(suppl 1):S158-S159.

20. Dailianas A, Skandalis N, Rimikis MN, Koutsomanis D, Kardasi M, Archimandritis A. Pelvic floor study in patients with obstructive defecation: influence of biofeedback. J Clin Gastroenterol 2000;30:176-180.

21. Pucciani F, Rottoli ML, Bologna A, et al. Pelvic floor dyssynergia and bimodal rehabilitation: results of combined pelviperineal kinesitherapy and biofeedback training. Int J Colorectal Dis 1998;13:124-130.

22. Lee BE, Kim GH. How to perform and interpret balloon expulsion test. J Neurogastroenterol Motil 2014;20:407-409. 